\title{
TURBIN ANGIN SAVONIUS EMPAT SUDU DENGAN VARIASI MODEL PROFIL SEBAGAI MEDIA BELAJAR MAHASISWA
}

\author{
Eka Sari Wijianti ${ }^{1}$, Saparin $^{2}$, Yudi Setiawan ${ }^{3}$ \\ 1,2,3 Jurusan Teknik Mesin, Fakultas Teknik, Universitas Bangka Belitung \\ Kampus Terpadu Universitas Bangka Belitung Merawang Kabupaten Bangka \\ Email : ekasariwijianti@yahoo.co.id
}

\begin{abstract}
Abstrak
Penelitian ini adalah tentang pembuatan purwarupa turbin angin savonius empat sudu sebagai media pembelajaran mata kuliah Mesin Konversi Energi di jurusan Teknik Mesin Fakultas Teknik Universitas Bangka Belitung. Pembuatan media pembelajaran ini dikarenakan keterbatasan fasilitas praktikum mahasiswa untuk menunjang keberlangsungan perkuliahan yang efektif dan kondusif. Purwarupa dibuat dengan dimensi yang kecil, yaitu dengan rangka $0,75 \mathrm{~m} \times 1,5 \mathrm{~m}$ dan diameter sudu turbin $0,15 \times 0,3 \mathrm{~m}$. Penelitian dibantu dengan kipas angin sebagai pembangkit energi angin, variasi kecepatan angin dilakukan pada 3 kecepatan dengan sesuai dengan kecepatan angin yang dibangkitkan oleh kipas yang diukur menggunakan anemometer. Putaran rotor yang dihasilkan diukur dengan tachometer sedangkan arus dan tegangan diukur menggunakan multitester. Sudu turbin divariasikan adalah 4 sudu dengan 3 model profil sudu yaitu U, L dan S. Penelitian nenunjukkan bahwa kecepatan angin memberikan pengaruh terhadap kinerja turbin. Semakin tinggi kecepatan angin, semakin tinggi putaran rotor dan daya yang dihasilkan. Profil terbaik diperoleh dari model L yang mencapai 177.63rpm dengan daya 6.35 watt.
\end{abstract}

Keywords: Turbin angin savonius, media pembelajaran, pembangkit listrik tenaga angin

\begin{abstract}
This research is about making a prototype of four blades savonius wind turbine as a learning media for Energy Conversion in the Mechanical Engineering Department, Bangka Belitung University. The making of this learning media is due to the limitations of student practicum facilities to support the continuity of practical and conducive lectures. The prototype was made with small dimensions, namely a frame of $0.75 \mathrm{~m} \times 1.5 \mathrm{~m}$ and a turbine blade diameter of $0.15 \times 0.3 \mathrm{~m}$. A fan-assisted the study as a wind energy generator. Wind speed variations carried out at three rates following the wind speed generated by the fan. The rate of wind speed measured using an anemometer and the rotation using a tachometer. The current and voltage are measured using a multitester. Turbine blades are varied with 4 blades with three-blade profile models, namely $U, L$, and $S$. Research, shows that wind speed influences turbine performance. The higher the wind speed, the higher the rotor's rotation, and so the resulting power. The best profile is obtained from the L model, which reaches 177.63 rpm with 6.35 watts of power.
\end{abstract}

Keywords: savonius wind turbine, learning media, wind power generation

\section{PENDAHULUAN}

Indonesia sebagai negara yang terletak di zamrud khatulistiwa memiliki banyak potensi sumber daya alam yang melimpah. Namun, saat ini Indonesia masih sangat bergantung pada sumber daya minyak bumi sebagai sumber energi utama [1]. Angin merupakan salah satu sumber energi terbarukan yang tersedia dengan melimpah di alam. Energi angin dapat dikonversikan menjadi energi listrik menggunakan turbin angin [2]. Pembangkit listrik tenaga angin ini bekerja dengan cara memutar poros turbin yang digerakkan oleh angin, outputnya adalah putaran poros/rotor. Poros ini dihubungkan ke generator. Generator inilah yang akan menghasilkan listrik. Listrik yang dihasilkan ini kemudian disimpan dalam sebuah baterai yang akan digunakan untuk keperluan menyalakan elektronik [3].

Pengembangan awal konversi energi umumnya bermula di lingkungan akademisi, melalui berbagai penelitian dengan merancang dan

57 Wijianti, Eka Sari, dkk; Turbin Angin Savonius Empat Sudu Dengan Variasi Model Profil Sebagai Media Belajar Mahasiswa 
membangun desain, model, purwarupa dan lainlain. Selain dosen, mahasiswapun berperan aktif untuk mengembangkan penelitian. Penelitian yang dilakukan oleh mahasiswa bermula dari kegiatan pembelajaran yang berasal dari perkuliahan teori dan praktikum. Praktikum memberikan pengalaman belajar yang lebih kangkrit jika dibandingkan dengan teori. Penggunaan media pembelajaran dan metode eksperimen akan membangkitkan motivasi belajar mahasiswa sehingga pembelajaran yang efektif akan tercapai. Namun, metode pembelajaran eksperimen harus ditunjang dengan media pembelajaran yang mumpuni [4].

Salah satu mata kuliah di jurusan Teknik Mesin Fakultas Teknik Universitas Bangka Belitung berdasarkan kurikulum 2014 adalah mata kuliah Mesin Konversi Energi. Mata kuliah ini kebanyakan penjelasan konsep secara teori. Salah satu penyebabnya adalah keterbatasan fasilitas praktikum. Belum ada sarana praktikum yang menunjang mata kuliah ini. Oleh karena itu untuk meningkatkan pemahaman mahasiswa dalam pembelajaran, melalui penelitian ini akan dibuat media pembelajaran berupa purwarupa turbin angin. Turbin angina terdiri dari dua macam, yaitu turbin angin sumbu vertical dan turbin angin sumbu horizontal. Turbin angin sumbu horizontal memerlukan angina dengan kecepatan yang tinggi dan penempatan di tempat yang tinggi pula, sedangkan turbin angin sumbu vertical hanya membutuhkan kecepatan angin rendah yang memanfaatkan gaya drag (gaya hambat) dan dapat ditempatkan di wilayah yang rendah pula[5][6]. Jenis turbin yang digunakan dalam penelitian ini adalah turbin angin sumbu vertikal. Turbin angin vertikal memiliki beberapa model, salah satunya adalah tipe savonius [7].

Turbin angin savonius dibuat dan diuji dalam skala laboratorium. Untuk menggerakkan turbin, akan menggunakan kipas angin dengan beberapa variasi kecepatan. Dari purwarupa turbin angin savonius ini diharapkan mahasiswa mampu memahami bagaimana prinsip kerja turbin angin savonius dan mengembangkan konsep tersebut kedalam kondisi sebenarnya yang dituangkan dalam bentuk penelitian.

\section{METODE PENELITIAN}

Penelitian ini menggunakan metode eksperimental. Satu model sudu dilakukan 3 kali pengujian untuk mendapatkan nilai rata-rata putaran rotor, tegangan dan arus listrik.

\section{Diagram alir}

Penelitian dilakukan berdasarkan tahapan dalam diagram alir berdasarkan gambar 1 .

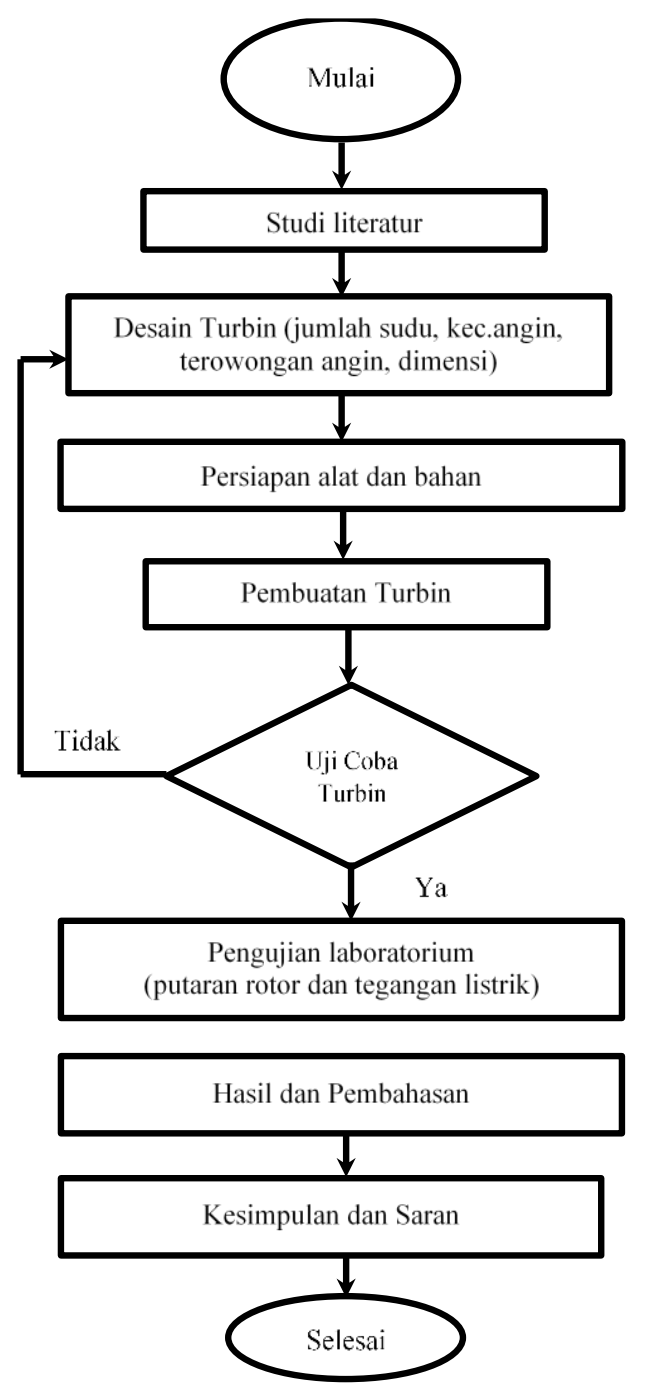

Gambar 1 Digram alir penelitian

\section{Desain turbin}

Turbin dibuat dengan diameter $300 \mathrm{~mm}$ dan tinggi 400mm. Pengujian dilakukan menggunakan terowongan angin sepanjang 1meter. Terowongan angina dibuat sederhana dan lurus, meskipun wind tunnel atau terowongan angin mempengaruhi kinerja turbin angin [8]. Kecepatan angin didapat berdasarkan kecepatan yang dibangkitkan oleh kipas angina, yaitu $2.9 \mathrm{~m} / \mathrm{s}, 3.2$ $\mathrm{m} / \mathrm{s}$, dan $3.3 \mathrm{~m} / \mathrm{s}$. Model profil yang akan diuji adalah profil $\mathrm{L}, \mathrm{U}$, dan $\mathrm{S}$ yang terbuat dari material alumunium dengan ketebalan $0,3 \mathrm{~mm}$ dan masingmasing memiliki 4 sudu lurus. Turbin ditumpu oleh rangka yang terbuat dari baja siku dan memiliki dimensi panjang $1600 \mathrm{~mm}$, lebar $400 \mathrm{~mm}$ dan tinggi $900 \mathrm{~mm}$.

58 Wijianti, Eka Sari, dkk; Turbin Angin Savonius Empat Sudu Dengan Variasi Model Profil Sebagai Media Belajar Mahasiswa 


\section{Konstruksi turbin}

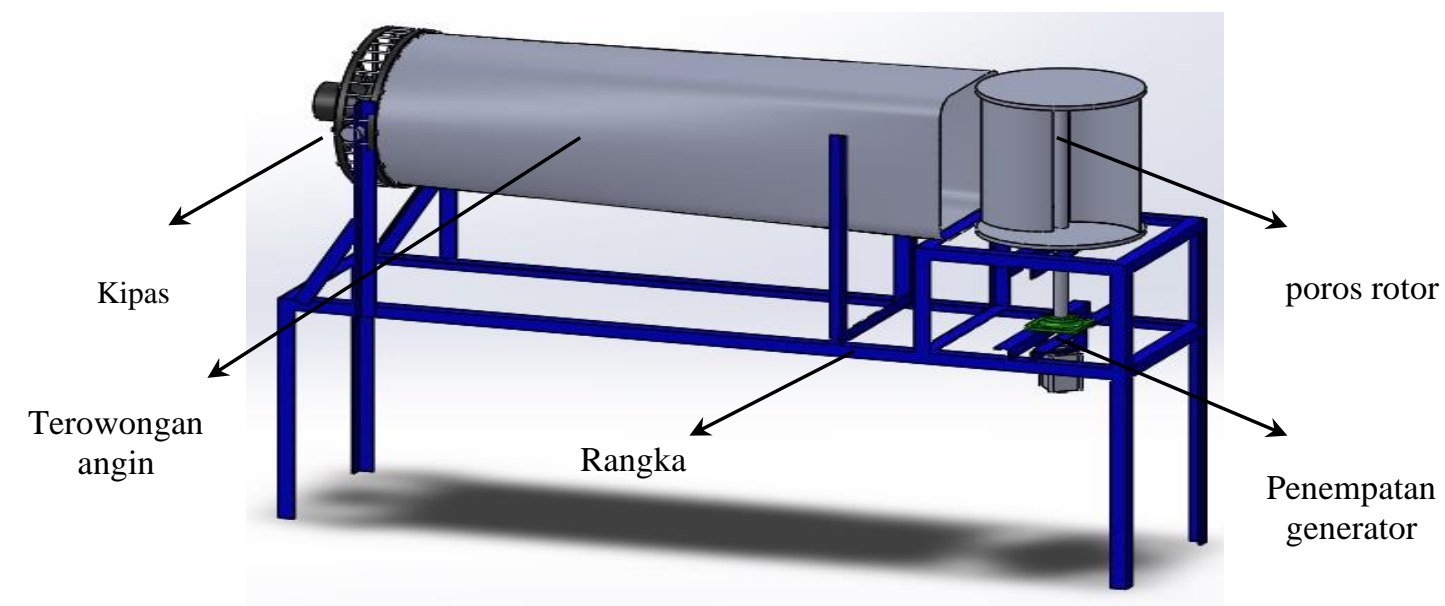

\section{Gambar 2 Instalasi penelitian}

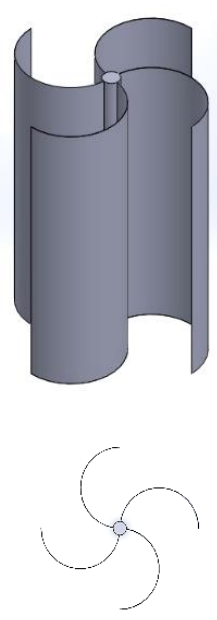

(a)

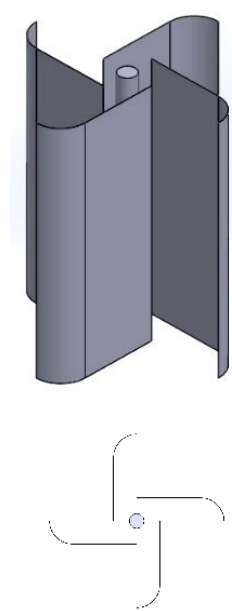

(b)
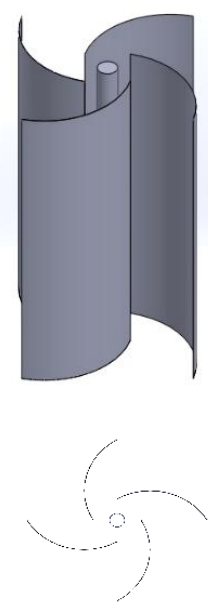

(c)

\section{Gambar 3 Model sudu yang digunakan a.Tipe} $\mathrm{U}$ b.Tipe $\mathbf{L}$ c.Tipe $\mathrm{S}$

Ketiga model profil turbin akan dibandingkan kinerjanya untuk mendapatkan jenis profil mana yang memiliki kinerja paling optimal.

\section{Cara kerja turbin}

Adapun prosedur kerja turbin adalah ketika angin dihembuskan dari blower dengan variasi kecepatan 2.9, 3.2, $3.3 \mathrm{~m} / \mathrm{s}$, kemudian akan mengenai sudu yang menyebabkan rotor akan berputar. Putaran poros rotor akan menggerakkan generator, disinilah akan muncul tegangan dan arus listrik. Pengukuran putaran dilakukan pada poros rotor dengan menggunakan tachometer, sedangkan tegangan dan arus listrik diukur menggunakan multitester.

\section{Rumus yang digunakan}

Untuk menentukan daya listrik digunakan rumus:

$$
\mathrm{P}_{\text {generator }}=\mathrm{V} \text {. I }
$$

dimana $\mathrm{P}$ dalah daya yang dibangkitkan oleh generator (watt), $\mathrm{v}$ adalah tegangan (volt) dan I adalah arus listrik (ampere).

Untuk menghitung daya turbin digunakan rumus:

$$
\mathrm{P}_{\text {angin }}=1 / 2 \rho . \text { A. } \mathrm{v}^{3} \text {. }
$$

dimana $\mathrm{P}_{\text {angin }}$ adalah daya teoritis turbin (watt), $\rho$ adalah massa jenis udara $\left(\mathrm{kg} / \mathrm{m}^{3}\right)$, A adalah luas permukaan bidang sapuan sudu turbin dan $\mathrm{v}$ adalah kecepatan angin $(\mathrm{m} / \mathrm{s})$.

$$
\begin{aligned}
& \text { untuk menghitung efisiensi turbin: } \\
& \eta=\frac{P_{\text {generator }}}{P_{\text {angin }}}
\end{aligned}
$$

dimana $\eta$ adalah efisiensi turbin.

\section{HASIL DAN PEMBAHASAN}

Berdasarkan penelitian turbin dengan jumlah sudu 4 dan model profil yang berbeda memiliki performance yang baik. Ketiga profil U, S dan L mampu berputar dengan cepat pada rentang putaran 129.3 sanpai $177.63 \mathrm{rpm}$. Kecepatan angin memberikan pengaruh terhadap kecepatan putar poros turbin. Semakin tinggi kecepatan angin, maka semakin besar putaran yang dihasilkan (gambar 4).

Tegangan yang dihasilkan oleh turbin juga sangat dipengaruhi oleh putaran rotor. Semakin tinggi putaran rotor, maka semakin tinggi tegangan

59 Wijianti, Eka Sari, dkk; Turbin Angin Savonius Empat Sudu Dengan Variasi Model Profil Sebagai Media Belajar Mahasiswa 
yang dihasilkan. Begitu juga dengan daya listrik yang dibangkitkan, semakin tinggi tegangan listrik yang dihasilkan maka daya listrik yang dihasilkan juga akan semakin tinggi (gambar 5).

Data penelitian menunjukkan bahwa kinerja turbin untuk sudu model $\mathrm{S}$ pada kecepatan angin $3.3 \mathrm{~m} / \mathrm{s}$ turbin mampu berputar pada kecepatan 168,8 rpm dengan menghasilkan tegangan 3,63 volt dan membangkitkan listrik 5.81 watt. Untuk profil U, pada kecepatan angin $3.3 \mathrm{~m} / \mathrm{s}$ mampu memutar turbin mencapai $144.56 \mathrm{rpm}$ dan menghasilkan listrik 3.3watt. Sedangkan untuk profil Lpada kecepatan angin $3.3 \mathrm{~m} / \mathrm{s}$ putaran poros mampu mencapai $177.63 \mathrm{rpm}$ dan menghasilkan daya 6.35 watt pada tegangan 4 volt (lihat tabel 1).

Model profil L memberikan kinerja yang lebih baik dibandingkan profil lainnya. Kinerja profil $\mathrm{L}$ yang baik ini disebabkan lengkungan $\mathrm{L}$ yang mampu mereduksi turbulen yang terjadi di ujung profil sudu, sehingga aliran angin yang terjadi di belakang proifil menjadi lebih halus, hal ini menyebabkan putaran turbin lebih ringan dan turbin akan berputar lebih cepat.

\section{Tabel 1 Data hasil pengujian}

\begin{tabular}{llll}
\hline \multirow{2}{*}{ Profil } & $\begin{array}{l}\text { Kecepatan } \\
\text { angin }(\mathrm{m} / \mathrm{s})\end{array}$ & $\begin{array}{l}\text { Putaran } \\
\text { poros }(\mathrm{rpm})\end{array}$ & $\begin{array}{l}\text { Tegangan } \\
\text { (volt) }\end{array}$ \\
\hline \multirow{3}{*}{$\mathrm{S}$} & 2.9 & 135.6 & 3.00 \\
\cline { 2 - 4 } & 3.2 & 151.03 & 3.47 \\
\cline { 2 - 4 } & 3.3 & 168.16 & 3.63 \\
\hline \multirow{3}{*}{$\mathrm{U}$} & 2.9 & 129.26 & 2.9 \\
\cline { 2 - 4 } & 3.2 & 129.3 & 2.9 \\
\cline { 2 - 4 } & 3.3 & 144.56 & 3.3 \\
\hline \multirow{2}{*}{$\mathrm{L}$} & 2.9 & 152.03 & 3.3 \\
\cline { 2 - 4 } & 3.2 & 167.96 & 3.7 \\
\hline & 3.3 & 177.63 & 4.0 \\
\hline
\end{tabular}

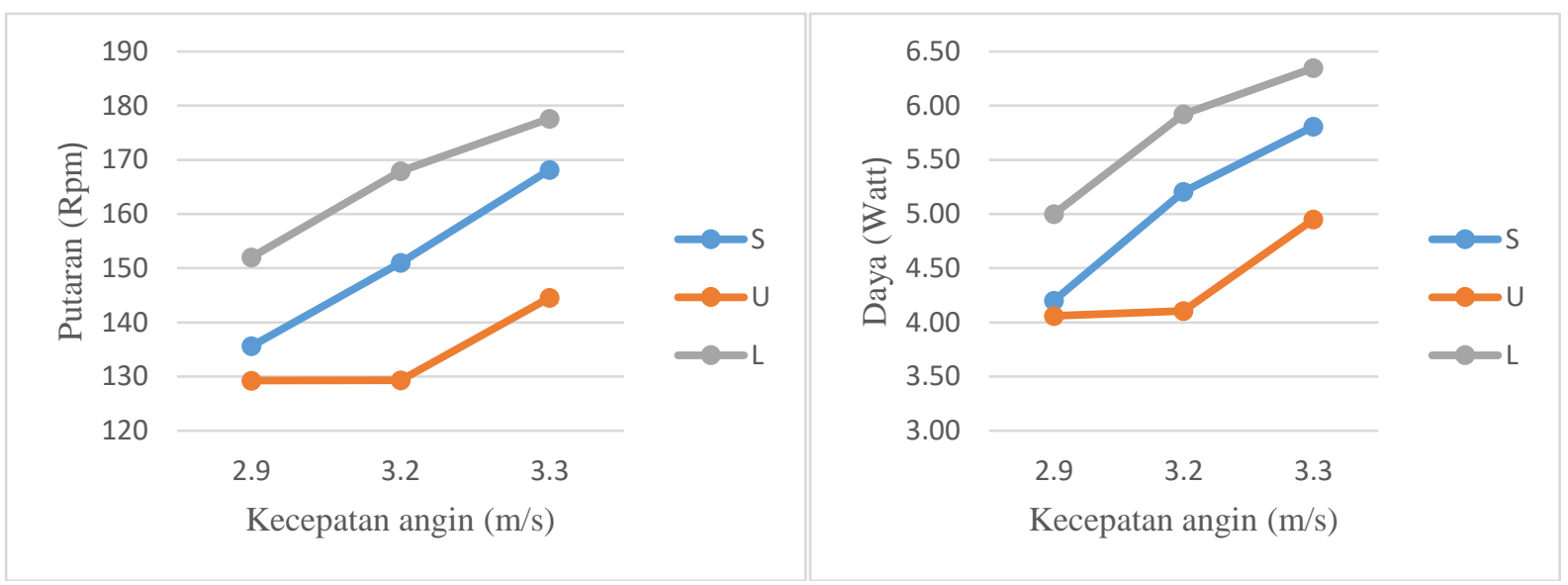

Gambar 4 Kecepatan angin vs putaran

Gambar 5 Kecepatan angin vs daya

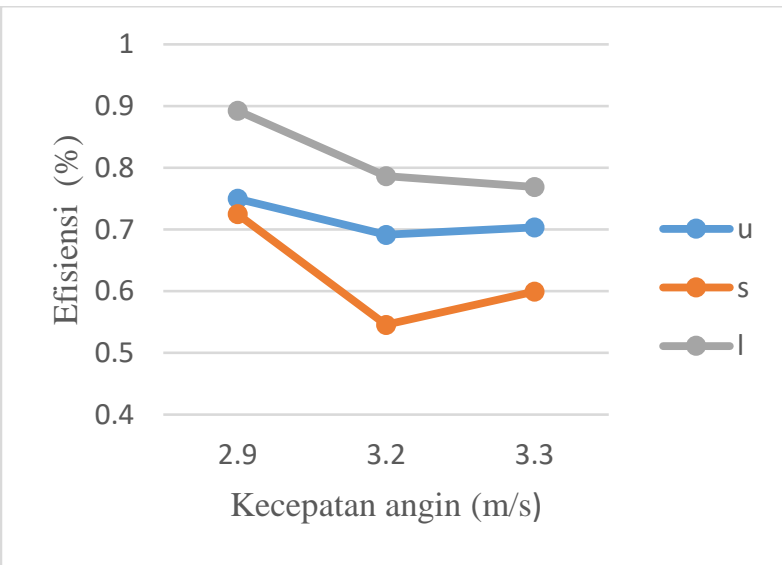

Gambar 6 Kecepatan angin vs efisiensi turbin

60 Wijianti, Eka Sari, dkk; Turbin Angin Savonius Empat Sudu Dengan Variasi Model Profil Sebagai Media Belajar Mahasiswa 
Tabel 2 Daya listrik yang dihasilkan dari berbagai tipe profil dan kecepatan angin

\begin{tabular}{ccccccc}
\hline \multirow{2}{*}{$\begin{array}{c}\text { Kecepatan } \\
\text { Angin (m/s) }\end{array}$} & \multicolumn{2}{c}{ Tipe S } & \multicolumn{2}{c}{ Tipe U } & \multicolumn{2}{c}{ Tipe L } \\
\cline { 2 - 7 }$($ Rpm) & $\begin{array}{c}\text { Daya } \\
\text { (Watt) }\end{array}$ & $\begin{array}{r}\text { Putaran } \\
(\text { Rpm })\end{array}$ & Daya (Watt) & $\begin{array}{r}\text { Putaran } \\
(\text { Rpm) }\end{array}$ & $\begin{array}{c}\text { Daya } \\
\text { (Watt) }\end{array}$ \\
\hline 3 & 135.60 & 4.20 & 129.26 & 4.06 & 152.03 & 5.00 \\
\hline 3,3 & 151.03 & 5.21 & 129.30 & 4.11 & 167.96 & 5.92 \\
\hline 3,5 & 168.16 & 5.81 & 144.56 & 4.95 & 177.63 & 6.35 \\
\hline
\end{tabular}

\section{KESIMPULAN}

Hasil penelitian berupa purwarupa turbin angin savonius empat sudu sebagai media pembelajaran mahasiswa telah selesai dilakukan. Turbin angin dapat bekerja dengan baik dan layak untuk dijadikan sebagai media pembelajaran. Penelitian menunjukkan bahwa:

1. Semakin tinggi kecepatan angin, semakin tinggi putaran rotor yang dihasilkan dan semakin tinggi pula daya yang dibangkitkan.

2. Jenis profil sudu memberikan pengaruh terhadap kinerja turbin. Model profil L mempunyai kinerja lebih baik dibandingkan profil $\mathrm{U}$ dan $\mathrm{S}$.

\section{PENGHARGAAN}

Penulis mengucapkan terima kasih kepada Universitas Bangka Belitung sebagai pemberi dana penelitian dengan skema program Penelitian Dosen Tingkat Jurusan (PDTJ) Tahun 2019.

\section{DAFTAR PUSTAKA}

[1] S. Teknik, M. Energi, F. Teknik, and U. N. Surabaya, "UJI EKSPERIMENTAL TURBIN ANGIN SUMBU VERTIKAL JENIS CROSS FLOW DENGAN VARIASI JUMLAH BLADE Moch Fachruddin Wahyu Permadi
Abstrak," JTM, vol. 06, no. Nomor 1, pp. 2531, 2005.

[2] E. Pane, "Optimasi perancangan turbin angin vertikal tipe darrieus untuk penerangan di jalan tol," no. November, pp. 1-2, 2017.

[3] I. S. Mulyana, J. Teknik, M. Fakultas, T. Industri, and U. Gunadarma, "Perancangan Turbin angin vertikal Savonius Sebagai Sumber Energi Untuk penerangan Jalan Tol," UG J., vol. 11 Nomor 3, p. 27, 2017.

[4] R. Sumiati, D. A. Zamri, S. Pengajar, J. Teknik, M. Politeknik, and N. Padang, "Rancang Bangun Miniatur Turbin Angin Pembangkit Listrik Untuk Media Pembelajaran," J. Tek. Mesin, vol. 3, no. 2, pp. 1-8, 2013.

[5] [5] C. I. Saputra, C. E. Rustana, and H. Nasbey, "PENGEMBANGAN TURBIN ANGIN SUMBU VERTIKAL TIPE TRIPLESTAGE SAVONIUS DENGAN POROS GANDA SNF2015-VII-43 SNF2015-VII-44," vol. IV, pp. 43-46, 2015.

[6] [6] M. H. Haqqqi, G. Nugroho, S. T. Mt, and A. Musyafa, "Rancang Bangun Turbin Angin Vertikal Jenis Savonius dengan Variasi Jumlah Blade Terintegrasi Circular Shield untuk Memperoleh Daya Maksimum," vol. 7, no. 7, pp. 1-6, 2013.

[7] [7] Hicary, Suwandi, and A. Qurthobi, "Analisis Pengaruh Jumlah Sudu Pada Turbin Angin Savonius Di Dalam Proses Pengisian Akumulator," vol. 3, no. 3, pp. 4911-4918, 2016.

[8] [8] A. M. Siregar, "RANCANG BANGUN WIND TUNNEL SEDERHANA UNTUK," vol. 2, no. 2, pp. 92-97, 2016.

61 Wijianti, Eka Sari, dkk; Turbin Angin Savonius Empat Sudu Dengan Variasi Model Profil Sebagai Media Belajar Mahasiswa 